\title{
Performance Analysis of a Large-Scale Steam Condenser Used in a Steam Power Plant
}

\author{
Mehmet Tontu (D) \\ Iskenderun Energy Production and Trade Company, Operation Department, 01680, Adana, Turkey
}

\begin{abstract}
This paper summarizes performance analysis of large-scale seawater-cooled box type condenser in a 660 MW steam power plant. Effect of seawater temperature and steam mass flow rate are investigated on the key performance parameters of steam condenser. Results indicated that improvement in the cooling water temperature generally is found favorable on the performance indicators of condenser. Condenser effectiveness improves by increasing of sea water temperature also its value enhances from 0.27 to 0.48 . On the contrary TTD value decreases accordingly. On the other hand, in the case of steam flow rate changing, effectiveness and overall heat transfer coefficient almost remain constant. Effectiveness of condenser isn't found as a function of steam flow variation. Moreover, steam power plant heat rate is investigated as a function of cooling water of condenser and thus it is seen to be decreased in the result of improvement of cooling water temperature. Conversely, power plant overall thermal efficiency decreases from $39.85 \%$ to $38.72 \%$ due to reduction of power generation.
\end{abstract}

Keywords: Steam condenser, Condenser performance, power plant, exergy destruction, heat load

\section{INTRODUCTION}

Condensation is a phase changing process by withdrawing of the latent heat of evaporation [1-2]. Condensation heat transfer has a significant duty in many industrial processes, such as thermal power plant, heavy industry, cooling and, air-conditioning cycles. Various physical processes are comprised in the condensation phenomena, their relative significance depending on the conditions and implementations [3-4].

Huge type water-cooled condenser is one of the highly critical equipment of thermal and nuclear power stations. Its effectiveness has a substantial influence on the whole steam power plant's thermal performance. [5-6]. Thermal energy losses from the steam power station are primarily because of heat ejection through the condenser. The condenser in a steam power station mostly utilizes either closed-cooling water cycle from a cooling tower to transfer low-grade waste heat to the environmental or once-through water from a river, lake or sea. Since the highest amount of energy loss in the steam power station is caused by heat expel from the condenser, the heat recovery, less fuel consumption and subsequent development in the power plant performance can be accomplished by decreasing thermal energy loss from condenser by optimizing cooling water flow parameters [7-
8]. However, weakness in the condenser circulating water parameters may cause an energy generation restriction due to lower vacuum pressure in the condenser. Thus, there is an essential to identify the optimal working parameters of condenser to obtain better efficiency of the thermal power stations and enhanced performance of the Rankine power cycle [9-10].

Recently, many related studies have been carried out which examine performance evaluation of steam condenser. Pattanayak et al. [9] investigated thermal performances of the steam surface condenser which is employed in the 210 MW capacity power plant. Heat transfer characteristics of condenser and its performances are examined using a modeling study by means of thermodynamic laws by changing key operating parameters of cooling water. Laskowski et al. [6] performed analysis to define performance variation of steam condenser against to upstream cooling water temperature, the cooling water mass flow rate and the steam mass flow rate. Actual data of this analysis is taken from currently running of $200 \mathrm{MW}$ capacity of power stations. Steam condenser efficiency, amount of heat transfer, vacuum pressure inside the chamber, and the performance and energy generation of the LP part of the steam turbine are assessed. Masiwal et al. [11] presented off-design performance evaluation
* Corresponding authour

Email: mtontu86@gmail.com 
and calculation methodology of a surface type condenser. Condenser performance study has been carried out for cooling water flow, cooling water inlet temperature, and air ingress/dirty tubes. In their work, all data for performance has been collected and evaluated from a $525 \mathrm{MW}$ operating unit of Bharat Heavy Electricals Limited. Anozie and Odejobi [7] conducted an optimization study to estimate the optimum circulation water flow rate of a condenser. Circulating water flowrate is vitally significant to ensure the highest performance and lowest running cost of the plant. In this work, software programs were developed for modeling of a power stations at several cooling water flowrate, to identify the optimal condenser circulating water flow rate for the cycle. The investigation indicated that working condenser at a reduced circulating water flow rate of $32,000 \mathrm{~m} 3 / \mathrm{h}$ instead of the base case scenario of $32,660 \mathrm{~m} 3 / \mathrm{h}$, reduced the overall heat transfer area requirement from $13,256 \mathrm{~m} 2$ to $8,113 \mathrm{~m} 2$, with the condenser making the maximum contribution to heat transfer area reduction. Harish et al [12] concentrated on improve a new model for adjusting smartly circulating seawater flow rate through condenser and illustrated of the use of this theoretical model with a given studies. Results indicated that less power consumption and better performance of power plant were provided by regulating pump speed compared to constant pump speed. Zeng at al. [13] analyzed condenser of $300 \mathrm{MW}$ capacity power plant numerically in terms of the flow and heat transfer performance. Three different type tube arrangements were considered. The three typical tube arrangements were investigated to improve a unique tube arrangement model. These outcomes demonstrate that the condenser effectiveness with the new tube arrangement is significantly improved.

Box type seawater-cooled large-scale steam surface condenser is generally preferred in the steam power plants and its effectiveness considerably affects the plant electricity production as well as the performance of the unit. This study attempts to show performance and heat transfer characteristics of huge type steam condenser used in $660 \mathrm{MW}$ capacity steam power plant. Characteristics of major operating parameters influencing the thermal performance of surface condenser in the steam power stations for several working conditions are examined. The effect of steam flow rate, seawater temperature and condenser vacuum pressure on heat rate and condenser performance are investigated through considering real operating data which is taken from the existing power plant. In addition to that the impact of climatic changes is shown to be important in the performance of condenser and also to compensate for the loss in plant efficiency. Climate considerations is also become even more significant particularly, seasonal transitions.

\section{SYSTEM DESCRIPTION}

In this analysis, the process flow taken into account is a typical 660 MW power capacity based on Rankine cycle having single reheat system with 4 low-pressure pre-heaters (LPH),
2 high-pressure pre-heaters (HPH), single flow high-pressure turbine (HPT), double-flow intermediate pressure turbine (IPT), 2 double-flow low-pressure turbines (LPT) and 2 identical condensers. Condenser is a fundamental element where the power generation by means of water-steam cycle [14]. It is a type of heat exchanger in which steam undergoes phase change by giving latent heat and converts into water. In turn, coolant water gains sensible heat. As the specific volume of steam is more than that of a specific volume of condensed water. A vacuum (negative pressure) develops in the shell side of condenser which extracts more steam from low-pressure turbine exhaust and thus creates a self-suction natural phenomenon. Condenser reduces the turbine exhaust pressure to increase the specific output of the turbine. The condenser has the function of condensing the steam exhausted from the last turbine stage to deaerate the accumulating condensate and to produce and maintain as high a vacuum as possible. Furthermore, it collects and condenses the steam produced at by-pass operation. The exhausted steam must be condensed to maintain circulation in the system. The condenser is designed for condensation at the lowest possible pressure, close to an absolute vacuum, and consequently for an increase in the usable thermal gradient in the turbine. The condenser cooling medium is seawater. To maintain the coefficient of heat transmission and to prevent deposits of corrosive substances as well as of mucous producing bacteria, the condenser tubes are continuously kept clean utilizing cleaning balls from the tube cleaning system.

The schematic of the steam condenser is as illustrated in Figure 1 . The condenser is a box-type surface condenser. The box-type construction of the steam space provides optimum utilization of the enclosed volume in terms of the heat transfer surface. Circulating seawater (CW) enters the tubes, through the tube sheet and the shell side of the condenser accepts wet-steam from exit of LPT. Steam flows over the shell side and circulating water flows through the tube side. The tube sides of the two condensers are series-connected. The circulating water heats up in the first condenser, is then routed to the second condenser and passes through this in the opposite direction whereby it is heated up still further. The condensers are divided on the tube side. The tubing is divided into two halves having identical functions. Each condenser half has its inlet and outlet water boxes for the circulating water. Two separate circulating water flows are therefore routed through the tubing. Both flows are routed through the condenser in a single pass. The arrangement of the condenser tubing within the steam space has a considerable influence on the efficiency of the condenser. The objectives are as follows: To provide a uniform distribution of the steam across the entire heat transfer surface, an optimum steam velocity between the tubes and to keep the pressure difference between the topmost and bottommost row of tubes as small as possible. Nominal operating parameters of steam condenser are shown in Table 1. 




Figure 1. The schematic of the steam condenser

Table 1. Nominal operating parameters of steam condenser

\begin{tabular}{|l|c|c|}
\hline Specifications & Unit & Amount \\
\hline Material & $\ldots--$ & Titanium \\
\hline Surface Area & $\mathrm{m}^{2}$ & 24013 \\
\hline Number of passes & $\ldots-.-$ & 1 \\
\hline Number of tubes & $\mathrm{pcs}$ & 20372 \\
\hline Dimensions of tube & $\mathrm{mm}$ & $28^{*} 0.5^{*} 13400$ \\
\hline Cooling water flow rate & $\mathrm{kg} / \mathrm{s}$ & 29000 \\
\hline Cooling water temperature & ${ }^{\circ} \mathrm{C}$ & $17-31$ \\
\hline Steam flow rate & $\mathrm{kg} / \mathrm{s}$ & 180 \\
\hline Operation pressure & $\mathrm{bar}$ & 0.04 \\
\hline
\end{tabular}

\section{ANALYSIS}

\subsection{Thermal Analysis}

Amount of heat transfer of condenser can be found in three different methods: through the energy balance for water (1), steam (2) or heat transfer rate in the condenser (3). Figure 2 illustrates condensation process and temperature changes through condenser lengths. The theory of thermodynamics needs that the rate of heat transfer from the steam be equal to the rate of heat transfer to the cooling water side. Also, different methods can be performed for thermal analysis of condenser. In this study, effectiveness of the condenser is investigated based on two different ways namely, logarithmic mean temperature difference (LMTD) method and $\varepsilon$-NTU method [15-16].

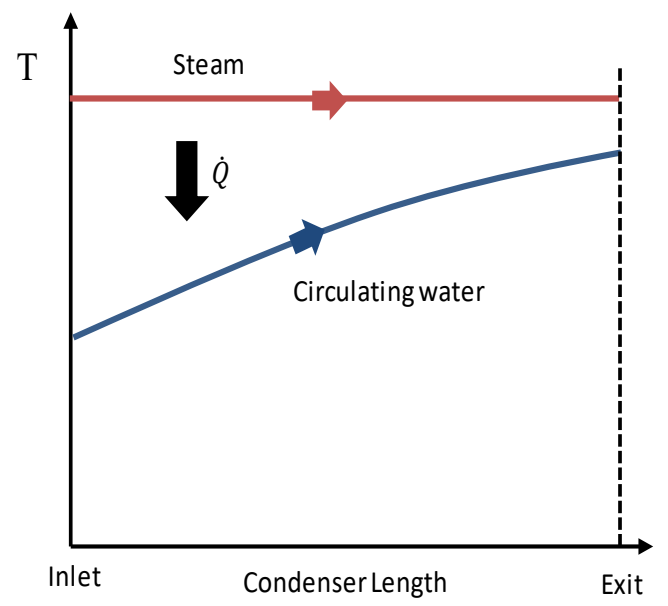

Figure 2. Condensation process and temperature changes through condenser lengths

$\dot{Q}=\dot{m}_{c w} \times c_{p, c w} \times\left(T_{c w, e}-T_{c w, i}\right)$

$$
\begin{aligned}
& \dot{Q}=\dot{m}_{s} \times h_{f g} \\
& \dot{Q}=U \times A \times \Delta T_{m} \\
& T T D=T_{s}-T_{c w, e}
\end{aligned}
$$

Table 2. Equations based on LMTD and -NTU methods

\begin{tabular}{|c|c|}
\hline LMTD & $\varepsilon-\mathrm{NTU}$ \\
\hline$\dot{Q}=U \times A \times \Delta T_{m}$ & $\dot{Q}=\varepsilon \times C_{\min } \times\left(T_{s}-T_{c u, i, i}\right)$ \\
\hline$\Delta T=\frac{\Delta T_{1}-\Delta T_{2}}{\ln \left(\Delta T_{1} / \Delta T_{2}\right)}$ & $C^{*}=\frac{C_{\min }}{C_{\max }}=\frac{\left(\dot{m} c_{p}\right)_{\min }}{\left(\dot{m} c_{p}\right)_{\max }}$ \\
\hline$\Delta T_{1}=T_{s}-T_{c u, e}$ & $N T U=\frac{U A}{C_{\min }}$ \\
\hline$\Delta T_{2}=T_{s}-T_{c o s, i}$ & $\varepsilon=1-\exp (-N T U)$ \\
\hline
\end{tabular}

Condensers are generally operated for long term with without performance loss and no alteration in their working conditions. So, condensers could be designed as steady-state flow components. As such, the mass flow rate of each fluid keeps constant, and the fluid features for example, temperature and velocity at any entrance or exit remain the same. Furthermore, the fluid streams experience little or no variations in their velocities and elevations, and hence the kinetic and potential energy differences are not considered. The specific heat of a fluid, generally, is variable with temperature. But, in a specified temperature range, it can be treated as a constant at some mean value with little loss inaccuracy. Axial heat conduction along the tube is normally unimportant and can be considered negligible. Finally, the external surface of the condenser is supposed to be adiabatic, so that in order to prevent heat transfer to the ambient, and heat transfer takes place between the two medium only [16].

\subsection{Exergy analysis}

The exergy analysis method is well-matched for furthering the objective of using more efficient energy sources, because it allows the location, cause and size of wastes to be recognized. This information can be used to design a new energy efficient system and improve the efficiency of existing systems. This approach will provide you to understand the properties of the exergy change during the heating process and to see which components have the greatest impact on system availability [17].

To understand the quality of an energy system, the second law of thermodynamics should be considered. The entropy change in a steady-state flow stream is revealed as; the sum of the entropy generation from the exergy destruction within system boundary, the net entropy transfer through the control volume by heat transfer and entropy change by mass flow across the boundaries which are also given below [1819]:

$$
\begin{aligned}
& \dot{S}_{\text {gen }}=\sum_{\text {out }} \dot{m} s-\sum_{\text {in }} \dot{m} s \\
& \dot{X}_{d}=T_{0} \times \dot{S}_{\text {gen }}
\end{aligned}
$$

The exergy equivalence at steady state situation is commonly expressed as the balance between the net exergy transfers by heat, work or mass flow through the boundaries of control volume and destructed exergy and exergy efficiency as 
stated in the following [20-21]:

$$
\dot{X}_{d}=\dot{X}_{\text {in }}-\dot{X}_{\text {out }}
$$

\section{RESULTS AND DISCUSSIONS}

This study is aimed to investigate performance of one of two identical condensers. In the first case, circulating sea water cooling inlet temperature to steam condenser was improved from $17^{\circ} \mathrm{C}$ to $31^{\circ} \mathrm{C}$, in two degree Celsius increments. The cooling water and steam mass flow rates are constant and equivalent to the nominal operating values.

The effect of the variation in the cooling water inlet temperature on the steam condenser heat rate and the exergy destruction rate are shown in Figure 3. Heat rejection to environmental linearly increases as seawater temperature increases. Heat load of condenser is the output of the combination of overall heat transfer coefficient and temperature differences between two medium therefore, heat rejection directly proportional to the seawater temperature. Conversely, exergy destruction in the condenser is positively influenced by the seawater incremental. Irreversibility in the condenser is mainly because of temperature differences between steam and seawater temperature so it is reduced with seawater enhancement. Moreover, heat rejection from condenser is thermodynamically insignificant due to heat source close to outside condition. Decline in the exergy destruction while increasing heat transfer is indicative of increased usable energy and seawater temperature increase also confirms this result.

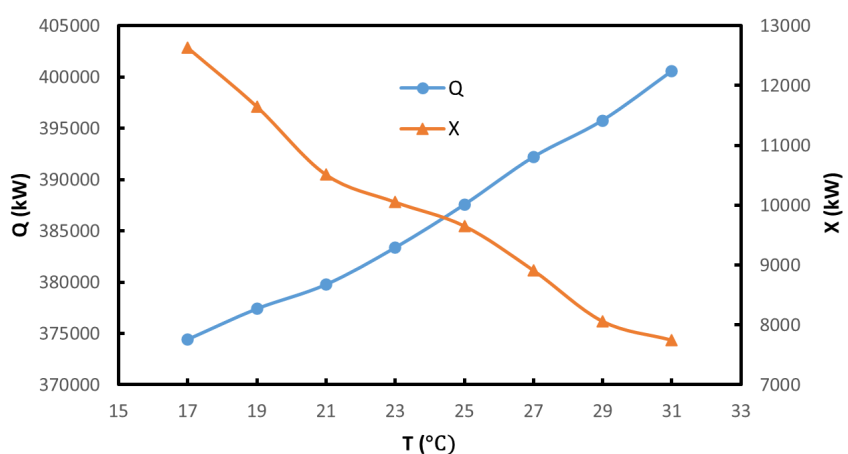

Figure 3. Variation of heat load and exergy destruction as a function of seawater temperatures

Figure 4 shows condenser TTD and effectiveness values as a function of cooling water inlet temperature. TTD is a measure of the efficiency with which heat is transferred from the steam side to the water side. A lower TTD is always better, and provides greater heat rate in the condenser and hence performance of condenser will enhance. Two main reasons for higher TTD: if there's an air removal problem, the air will collect in the condenser and reduce the effective area for the heat to transfer across the two working fluids of the exchanger. Another common reason for higher TTD occurs over a greater amount of time and isn't so instant would be heat exchanger fouling. The build up inside of the tubes can reduce cross section area as well so the fluids pass one another faster through choking and don't allow for the proper heat transfer time needed.

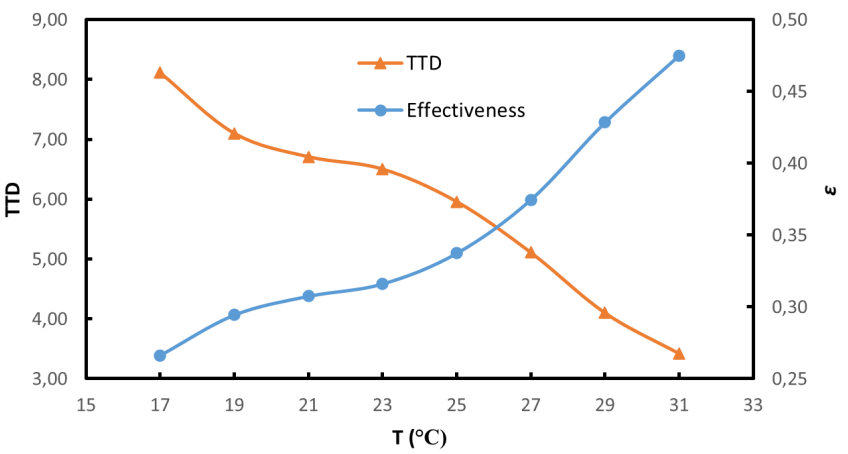

Figure 4. Condenser TTD and effectiveness values as a function of cooling water inlet temperature

Figure 5 indicates the impact of cooling water inlet temperature on condenser pressure and heat transfer coefficient. Increase in the $\mathrm{CW}$ temperature causes rise in the condenser pressure for a considered CW flow rate. Heat transfer coefficient enlarges with enhance in $\mathrm{CW}$ temperature from $17{ }^{\circ} \mathrm{C}$ to $31{ }^{\circ} \mathrm{C}$. As obtained, the mathematical relation of $\mathrm{CW}$ inlet temperature with heat transfer coefficient is found to be nonlinear but quadratic in nature, whereas with condenser operating pressure the relation is exponential. Overall heat transfer coefficient increases by virtue of condenser steam temperature is enhanced as response of an increase of condenser working pressure. The pressure in the large-scale condenser is highly depend on condenser structures, the amount of latent heat to be removed, CW temperature and flow rate, maintenance of the condenser and air removal system as well as sealing system.

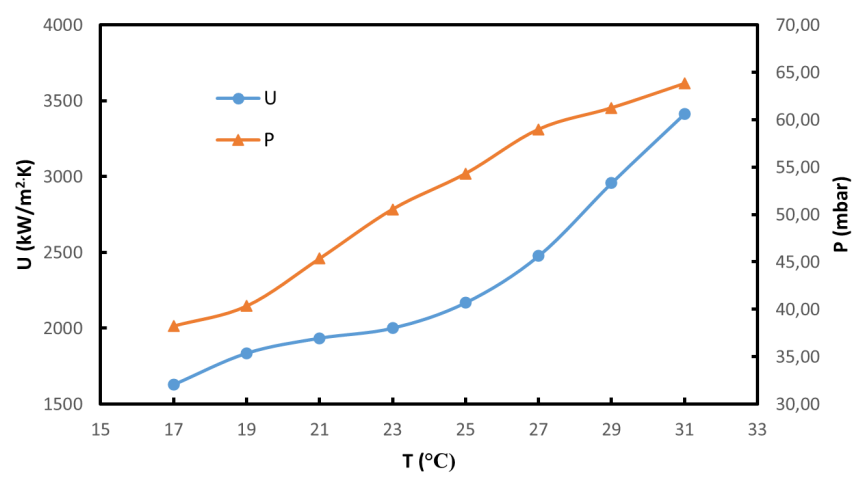

Figure 5. The relationship of cooling water inlet temperatures on condenser heat transfer coefficient and condenser pressure

Condenser cooling water inlet temperature is vital importance for both heat rate and power plant efficiencies. As it is seen from figure 6, power plant thermal efficiencies and heat rate are directly depend on CW inlet temperature variation. Higher inlet cooling water temperature causes worse condenser pressure and the power plant consumes additional coal to produce desired unit load. Condenser pressure and turbine power are negative correlated. An increase in condenser pressure leads to enthalpy rise at the outlet of the LP turbine therefore adversely affect electricity production. The enhancement in heat transfer is because of the higher steam flow required to keep target energy generation with the increase of cooling water temperature. 
Table 3. Effect of steam flow variation on the condenser performance indicators

\begin{tabular}{|c|c|c|c|c|c|c|c|c|c|}
\hline $\begin{array}{c}\text { Steam flow } \\
(\mathrm{kg} / \mathrm{s})\end{array}$ & $\begin{array}{c}\text { Vacum pressure } \\
(\mathrm{mbar})\end{array}$ & $\begin{array}{c}\mathrm{CW} \text { inlet temp. } \\
\left({ }^{\circ} \mathrm{C}\right)\end{array}$ & $\begin{array}{c}\Delta \mathrm{T}_{\mathrm{r}} \\
\left({ }^{\circ} \mathrm{C}\right)\end{array}$ & $\begin{array}{c}\mathrm{CW} \text { Flow rate } \\
(\mathrm{kg} / \mathrm{s})\end{array}$ & $\begin{array}{c}\mathrm{Q} \\
(\mathrm{kW})\end{array}$ & $\varepsilon$ & $\begin{array}{c}U \\
(\mathrm{~kW} / \mathrm{kg} \cdot \mathrm{K})\end{array}$ & $\begin{array}{c}\mathrm{X}_{\mathrm{D}} \\
(\mathrm{kW})\end{array}$ & $\begin{array}{c}\text { TTD } \\
\left({ }^{\circ} \mathrm{C}\right)\end{array}$ \\
\hline 190 & 38.92 & 17 & 3.17 & 29000 & 385287 & 0.28 & 1667 & 13020 & 8.13 \\
\hline 180 & 36.81 & 17 & 3.06 & 29000 & 371482 & 0.28 & 1613 & 12362 & 8.14 \\
\hline 170 & 35.89 & 17 & 2.89 & 29000 & 351301 & 0.28 & 1673 & 11069 & 7.38 \\
\hline 160 & 35.37 & 17 & 2.79 & 29000 & 338807 & 0.28 & 1690 & 10131 & 7.03 \\
\hline 150 & 34.58 & 17 & 2.67 & 29000 & 323981 & 0.28 & 1663 & 9519 & 6.85 \\
\hline 140 & 33.38 & 17 & 2.51 & 29000 & 304723 & 0.28 & 1646 & 8414 & 6.52 \\
\hline
\end{tabular}

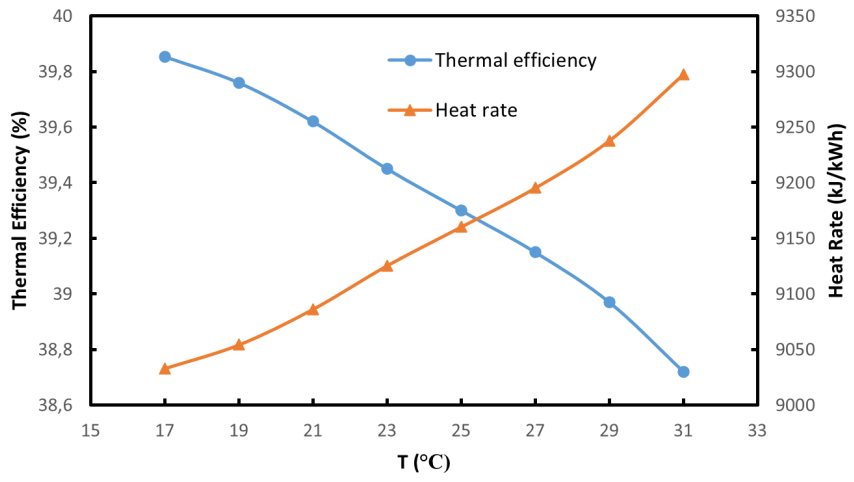

Figure 6. Effect of cooling water inlet temperature on the plant thermal efficiency and heat rate

Table 3 presents steam flow variation on the condenser performance indicators at constant $\mathrm{CW}$ temperature and flow rate. Steam power plant unit can vary against to load demand of dispatch center so steam inlet to condenser is changed. Heat rejection and exergy destruction decreases due to decline in the temperature of $\mathrm{CW}$ side resulting from steam flow reduces. Vacuum pressure is adversely affected by increasing from steam flow rate. Because, average temperature of $\mathrm{CW}$ temperature increase and hence condenser operating pressure is deteriorated. TTD value also decreases however, effectiveness and overall heat transfer coefficient almost remain constant. Effectiveness of condenser isn't found as a function of steam flow variation.

\section{CONCLUSIONS}

Condenser is the one of the most significant component of thermal power stations. The outputs and performance of steam power plant considerably depends on the condenser working criteria. This paper assessed all the aspects of condenser which affecting the performance of power plant. The dependency of cooling water temperature and steam mass flow rate with heat transfer coefficient, condenser pressure and heat transfer rate is established for a $660 \mathrm{MW}$ power plant condenser. The variation in cooling water-side parameters influence the typical factors which describe the condenser performance, such as the effectiveness, the amount of heat transfer, and the condenser operating pressure, which has a substantial impact on the efficiency of condenser. Main findings are summarized as follows:

- Increase of cooling water temperature improves steam condenser performance parameters from thermal assessment point of view.

- Variation of steam flow rate doesn't affect intensely condenser performance however; steam flow rate changing directly influences exergy destruction and heat load of condenser.

- Cycle efficiency of coal-fired power plant improves with cooling water reduction of condenser since turbines converts more heat into electricity.

\section{REFERENCES}

[1] Strusnik, D., Golob, M., Avsec, J. (2016). Effect of non-condensable gas on heat transfer in steam turbine condenser and modelling of ejector pump system by controlling the gas extraction rate through extraction tubes. Energy Conversion and Management, 126: 228246.

[2] Haldkar, V., Sharma, A.S, Ranjan, R.K., Bajpai, V.K. (2013). An energy analysis of condenser. International Journal of Thermal Technologies, 3: 120-125.

[3] Mirzabeygi, P. Zhang, C. (2015). Three-dimensional numerical model for the two-phase flow and heat transfer in condensers. International Journal of Heat and Mass Transfer, 81: 618-637.

[4] Mathurkar, R. D., Lawankar, Dr. S. M. (2017). Review on steam condensation heat transfer coefficient in vertical mini diameter tube. International Research Journal of Engineering and Technology, 4: 705-710.

[5] Viola, V. M., Pavkovic, B., Mrzljak. (2018). Numerical model for on-condition monitoring of condenser in coal-fired power plants. International Journal of Heat and Mass Transfer, 117: 912-923.

[6] Laskowski, R., Smyk, A., Lewandowski, J., Rusowicz, A. (2015). Cooperation of a steam condenser with a low-pressure part of a steam turbine in off-design conditions, American Journal of Energy Research, 3: 13-18.

[7] Anozie, A.N., Odejobi, O.J. (2011). The search for optimum condenser cooling water flow rate in a thermal power plant. Applied Thermal Engineering, 31: 4083-4090.

[8] Sikarwar, A.S., Dandotiya, D., Agrawal, S.K. (2013). Performance analysis of surface condenser under various operating parameters. International Research Journal of Engineering Reserarch and Aplications, 3: 416-421.

[9] Pattanayak, L., Padhi, B.N., Kodamasing, B. (2019). Thermal performance assessment of steam surface condenser. Case Studies in Thermal Engineering, 14: 100484.

[10] Nebot, E., Casanueva, J.F., Casanueva, T., Sales, D. (2007). Model for fouling deposition on power plant steam condensers cooled with seawater: Effect of water velocity and tube material. International Journal of Heat and Mass Transfer, 50: 3351-3358.

[11] Masiwal, G., Kumar, P.S., Chaudhary, S. (2017). Performance analysis of surface condenser in 525MW thermal power plant. International Research Journal of Engineering and Technology, 9: 1931-1939. 
[12] Harish, R., Subhramanyan, E. E., Madhavan, R., Vidyanand, S. (2010), Theoretical model for evaluation of variable frequency drive for cooling water pumps in sea water based once through condenser cooling water systems, Applied Thermal Engineering, 30: 2051-2057.

[13] Zeng, H., Meng, J., Li, Z. (2012). Numerical study of a power plant condenser tube arrangement, Applied Thermal Engineering, 40: 294-303.

[14] Tontu, M., Bilgili, M., Sahin, B. (2018). Performance analysis of an industrial steam power plant with varying loads. International Journal of Exergy, 27(2): 231-250.

[15] Kakac, S. (1991). Boilers evaporators and condensers, John wiley \& sons, Newyork.

[16] Çengel, A.Y., Ghajar, A. J. (2015). Heat and mass transfer: fundamentals \& applications, Mc Graw-Hill, Newyork.

[17] Aysakhanam, D., Patel, I.J. (2014). Exergy analysis of inlet water temperature of condenser. International Research Journal of Engineering Reserarch and Aplications, 4: 249-252.

[18] Ameri, M., Ahmadi, P., Hamidi, A. (2009). Energy, exergy and exergoeconomic analysis of a steam power plant: A case study. International Journal of Energy Research, 33: 499-512.

[19] Oztürk, M.M., Erbay, B. (2016). Transient exergy analysis of the condenser and evaporator of an air source heat pump water heater. Journal of Mechanics Engineering and Automation, 6: 339-347.

[20] Bilgili, M., Çardak, E., Aktaş, A. E. (2017). Thermodynamic Analysis of Bus Air Conditioner Working with Refrigerant R600a. European Mechanical Science, 1(2): 69-75.

[21] Kurtulmuş, N., Horuz, I. (2017). An industrial vapor absorption air conditioning application. Journal of Thermal Science and Technology, 37(2): 49-60.

\section{Nomenclature}

$\begin{array}{ll}\dot{X} & : \text { Exergy }(\mathrm{kW}) \\ \dot{Q} & : \text { Heat rate }(\mathrm{kW}) \\ \dot{m} & : \text { Mass flow rate }(\mathrm{kg} / \mathrm{s}) \\ \mathrm{T} & : \text { Temperature }\left({ }^{\circ} \mathrm{C}\right) \\ \mathrm{h} & : \text { Enthalpy }(\mathrm{kJ} / \mathrm{kg}) \\ \dot{S} & : \text { Entropy }(\mathrm{kW}) \\ \mathrm{TTD} & : \text { Terminal Temperature Difference }\left({ }^{\circ} \mathrm{C}\right) \\ \mathrm{U} & : \text { Overall heat transfer coefficient }(\mathrm{kW} / \mathrm{kg} \cdot \mathrm{K}) \\ \mathrm{P} & : \text { Pressure }(\mathrm{mbar}) \\ \varepsilon & : \text { Effectiveness }\end{array}$

\section{Subscript}

$\begin{array}{ll}c w, i & : \text { Circulating water inlet } \\ c w, o & : \text { Circulating water outlet } \\ \mathrm{s} & : \text { Steam } \\ \mathrm{d} & : \text { Destruction } \\ \text { in } & : \text { Input } \\ \text { out } & : \text { Output } \\ \text { gen } & : \text { Generation } \\ \min & : \text { Minimum } \\ \max & : \text { Maximum }\end{array}$

